\title{
A Multiple Discrete-Continuous Model for Independent- and Joint- Discretionary-Activity Participation Decisions
}

\author{
Sivaramakrishnan Srinivasan \\ (Corresponding author) \\ University of Florida \\ Department of Civil and Coastal Engineering \\ 365 Weil Hall, PO Box 116580 \\ Gainesville, FL 32608 \\ Tel 352-392-9537 Extn. 1456 \\ Fax: 352-392-3394 \\ E-mail: siva@ce.ufl.edu
}

\&

\section{Chandra R. Bhat}

The University of Texas at Austin

Dept of Civil, Architectural \& Environmental Engineering

1 University Station C1761

Austin, TX 78712-0278

Tel: 512-471-4535

Fax: 512-475-8744

E-mail: bhat@mail.utexas.edu 


\begin{abstract}
This paper presents a multiple discrete-continuous econometric structure to model the daily time-investment decisions of couples in solo- and joint- discretionary activities incorporating intra-personal and inter-personal inter-dependencies. The empirical model was estimated using data from the 2000 Bay Area Travel Survey. The results indicate evidence of the positive impact of vehicle availability on independent activity participation and the negative impacts of the presence of children and mandatory time investments on the joint discretionary-activity engagement of the spouses. In addition, we also find the mandatory- and maintenance- activityparticipation characteristics of the spouse to influence the discretionary activity choices of individuals. Finally, the analysis also indicates a strong impact of common unobserved factors on the decisions of couples. From a policy analysis perspective, these results imply that demand-management actions directly impacting one adult could also result in changes to the activity patterns of his/her spouse and to changes in joint activity participation characteristics.
\end{abstract}

\title{
KEYWORDS
}

Discretionary activities, Intra-household interactions, Multiple discrete-continuous models 


\section{INTRODUCTION AND RESEARCH OBJECTIVES}

Household members interact in many ways during their daily activity- and travelrelated decision-making. Consequently, the activity-travel patterns of all household members become inter-dependent. There has been an increasing realization that such household interdependencies have to be accommodated explicitly within activity-based models for accurate forecasts of travel patterns and for the realistic evaluation of the impacts of policy actions [see, for example, Vovsha et al. (2005) and Srinivasan and Bhat (2005)]. As a result, during the last few years, there have been a significant number of studies aimed at the modeling of household interactions, including Pribyl and Goulias (2005), Srinivasan and Athuru (2005), Goulias and Kim (2005), Gliebe and Koppleman $(2005,2002)$, Vovsha et al. (2003), and Scott and Kanaroglou (2002). The reader is referred to Srinivasan (2004) for a recent synthesis of the state-of-the-art in accommodating household interactions in activity-based analysis.

This paper contributes to the growing area of the analysis of household interdependencies in activity-travel patterns by examining solo and joint discretionary activity participation (time use) decisions. Specifically, the objective of this paper is to analyze the daily discretionary activity time-investment decisions of couples in nuclear-family households incorporating (1) intra-personal trade-offs between in-home and out-of-home activity participation decisions, (2) inter-personal trade-offs between solo and joint activity participation decisions, and (3) the effects of common unobserved factors (including habits, influence, and altruism) on the decisions of the spouses. The resulting choice structure has a multiple discrete-continuous form. This is because of the simultaneous analysis of multiple decisions of household members and the need to accommodate substantial number of observations with zero time investments (because not all individuals undertake discretionary activities on a daily basis). This paper also 
contributes methodologically by formulating a flexible econometric structure for the modeling of multiple discrete-continuous choices.

\section{ECONOMETRIC MODEL STRUCTURE AND ESTIMATION PROCEDURE}

The discretionary activity generation involves the simultaneous modeling of the following five discrete-continuous choices (Figure 1): (1) the male's decision to undertake independent activities in-home $(\mathrm{IH})$ and the corresponding duration, (2) the female's decision to undertake independent activities in-home and the corresponding duration, (3) the male's decision to undertake independent activities out-of-home $(\mathrm{OH})$ and the corresponding duration, (4) the female's decision to undertake independent activities out-of-home and the corresponding duration, and (5) the household's decision to undertake joint activities out-of-home and the corresponding duration (Joint in-home activities are not included in this analysis only because it was not possible to clearly identify such episodes from the survey data). The discrete components of the choices (i.e., the decision to undertake activity) are each modeled using the binary logit structure. The continuous components of the choices (i.e., the activity duration) are each modeled using a linear regression structure with the natural logarithm of the corresponding activity duration as the choice variable.

The need to consider the impact of an individual's choices on her/his spouse's activity participation choices and, in turn, the impact of the spouse's activity participation on the individual's choices leads to linkages between the discretionary activity participation choices of the male and the female heads. Further, household heads make trade-offs between in-home and out-of-home solo activity participation (intra-personal tradeoffs) and also between solo and joint activity participation (inter-personal tradeoffs). These linkages and tradeoffs are represented using error correlations across the five discrete-continuous choices leading to a multiple binary logit/ linear regression discrete- 
continuous model. The detailed econometric structure of this model and the estimation procedure are discussed below.

Let $i$ represent the index for the five discrete-continuous choices, which can be one of the following: (1) male's independent in-home choices $(i=M I H),(2)$ female's independent in-home choices $(i=F I H)$, (3) male's independent out-of-home choices $(i=\mathrm{MOH}),(4)$ female's independent out-of-home choices $(i=F O H)$, and (5) household's joint out-of-home choices $(i=J O H)$.

The discrete components of the model are specified using the binary logit structure. The corresponding utility functions are:

$U_{i q}=\beta_{i} Z_{i q}+\omega_{i q}-\varepsilon_{i q}$,

where, $U_{i q}$ is the indirect utility that individual(s) in household $q$ derives from undertaking activity corresponding to type $i$. For example, $U_{M I H q}$ is the utility derived by the male from undertaking in-home solo discretionary activities and $U_{\mathrm{JOHq}}$ is the utility derived from undertaking joint out-of-home discretionary activities. Further, we assume that the utility derived from not undertaking activities is zero. $Z_{i q}$ is the vector of exogenous variables for household $q$ and alternative $i$, and $\beta_{i}$ is the vector of coefficients on exogenous variables (for alternative $i$ ). $\omega_{i q}$ and $\varepsilon_{i q}$ are stochastic error terms. Assume that the vector $\omega_{q}=\left[\omega_{M I H q}, \omega_{F I H q}, \omega_{M O H q}, \omega_{F O H q}, \omega_{J O H q}\right]$ is multivariate normal with a mean vector of zero and covariance matrix $\Sigma$. Identification of the parameters in discrete choice models require that the scale of the utility function be fixed. As a consequence, we fix the variance terms (i.e., the diagonal elements) in the covariance matrix $\Sigma$ as 1 . Further, $\omega_{q}$ is also assumed to be independently and identically distributed across households.

The error term $\varepsilon_{i q}$ is assumed to be independently and identically logistically distributed across the alternatives $i$ and households $q$ (this assumption leads to the 
binary logit structure for each of the discrete choices, conditional on $\omega_{q}$ ). Let $F_{i}\left(\varepsilon_{i q} \mid \omega_{q}\right)$ represent this cumulative density function.

Defining a dichotomous variable $R_{i q}$ such that $R_{i q}=1$ if household $q$ chooses to undertake activity corresponding to type $i$ and 0 otherwise, the conditional probability (conditional on $\omega_{q}$ ) that household $q$ chooses to undertake activity corresponding to type $i$ is given by:

$\operatorname{Prob}\left(R_{i q}=1 \mid \omega_{q}\right)=F_{i}\left(\beta_{i} Z_{i q}+\omega_{i q} \mid \omega_{q}\right)=\frac{\exp \left(\beta_{i} Z_{i q}+\omega_{i q}\right)}{1+\exp \left(\beta_{i} Z_{i q}+\omega_{i q}\right)}$

The choice of activity duration conditional on the decision of undertaking activities of each of the types (i.e., $i=\mathrm{MIH}, \mathrm{FIH}, \mathrm{MOH}, \mathrm{FOH}$, and $\mathrm{JOH}$ ) is modeled using a linear regression system. This set of five regression equations can be specified as follows:

$d_{i q}=\theta_{i} X_{i q}+\eta_{i q}$

where $d_{i q}$ is the natural logarithm of the duration corresponding to activity of type $i$, (for example, $d_{M I H q}$ is the male's independent in-home activity duration and $d_{J O H q}$ is the joint out-of-home activity duration). $X_{i q}$ is a vector of exogenous variables, and $\theta_{i}$ is the vector of coefficients on these exogenous variables. Assume that the stochastic error terms, $\eta_{i q}$, are independently and identically normal-distributed across households with mean zero and variance $\sigma_{\eta i}^{2}$. These error terms are also assumed to be independently distributed across $i$, i.e., the five choices (This implies that correlations across the five continuous components are not accommodated in this formulation).

The probability of choosing activity duration of $t_{i q}$, corresponding to the activity type $i$, is given by:

$\operatorname{Prob}\left(d_{i q}=t_{i q}\right)=\phi\left(\frac{t_{i q}-\theta_{i} X_{i q}}{\sigma_{\eta i}}\right)$ 
where, $\phi$ is the standard normal probability distribution function.

We assume that the error terms $\eta_{i q}$ and $\varepsilon_{i q}$ are correlated for each $i$ which generates the "jointness" between the discrete and continuous components of the choices. This correlation could be because of common unobserved factors impacting both the participation choice and the duration of participation.

The likelihood function can be constructed by converting the non-normal error terms in the discrete choice utility expressions $\left(\varepsilon_{i q}\right)$ into standard normal random variables (Lee, 1983):

$$
\varepsilon_{i q}^{*}=\Phi^{-1}\left[F_{i}\left(\varepsilon_{i q} \mid \omega_{q}\right)\right]
$$

Next, define $\rho_{i}$ as the correlation between $\varepsilon_{i q}^{*}$, the (transformed) normal error term in the discrete part of the model system and $\eta_{i q}$, the error term in the continuous duration part of the model system (for $i=\mathrm{MIH}, \mathrm{FIH}, \mathrm{MOH}, \mathrm{FOH}$, and $\mathrm{JOH}$ ). The joint normal distribution between $\varepsilon_{i q}^{*}$ and $\eta_{i q}$ can, therefore, be specified as:

$$
\left(\varepsilon_{i q}^{*}, \eta_{i q}\right) \sim N_{2}\left(0,0,1, \sigma_{\eta i}^{2}, \rho_{i}\right)
$$

Finally, from Equations 2, 4, and 6, the probability that household $q$ chooses to undertake activity of type $i$ (for $i=\mathrm{MIH}, \mathrm{FIH}, \mathrm{MOH}, \mathrm{FOH}$, and $\mathrm{JOH}$ ) and a corresponding duration $t_{i q}$ (and conditional on $\omega_{q}$ ) is given by:

$\operatorname{Prob}\left(R_{i q}=1 \& d_{i q}=t_{i q} \mid \omega_{q}\right)=\frac{1}{\sigma_{\eta i}} \Phi\left(b_{i q}\right) \phi\left(g_{i q}\right)$

where,

$$
\begin{aligned}
& g_{i q}=\left(\frac{t_{i q}-\theta_{i} X_{i q}}{\sigma_{\eta i}}\right) \\
& b_{i q}=\left(\frac{\Phi^{-1}\left(F_{i}\left(\beta_{i} Z_{i q}+\omega_{i q} \mid \omega_{q}\right)\right)-\rho_{i} g_{i q}}{\sqrt{1-\rho_{i}^{2}}}\right)
\end{aligned}
$$


Further, the probability that household $q$ does not undertake activity of type $i$ (for $i$ $=\mathrm{MIH}, \mathrm{FIH}, \mathrm{MOH}, \mathrm{FOH}$, and $\mathrm{JOH}$ ), conditional on $\omega_{q}$ is given by:

$$
\operatorname{Prob}\left(R_{i q}=0 \mid \omega_{q}\right)=1-F_{i}\left(\beta_{i} Z_{i q}+\omega_{i q} \mid \omega_{q}\right)=\frac{1}{1+\exp \left(\beta_{i} Z_{i q}+\omega_{i q}\right)}
$$

Therefore, from Equations 7 and 8, the conditional likelihood function for any activity of type $i$ and household $q$, is given by:

$$
L_{i q} \mid \omega_{q}=\left[\operatorname{Prob}\left(R_{i q}=0 \mid \omega_{q}\right)\right]^{1-R_{i q}}\left[\operatorname{Prob}\left(R_{i q}=1 \& d_{i q}=t_{i q} \mid \omega_{q}\right)\right]^{R_{i q}}
$$

The overall conditional likelihood function for household $q$ is then the product of the likelihood functions for each activity type:

$$
L_{q} \mid \omega_{q}=\prod_{i}\left(L_{i q} \mid \omega_{q}\right)
$$

The unconditional likelihood function can now be obtained by integrating over the elements in the vector $\omega_{q}$ :

$$
L_{q}=\int_{\omega_{q}}\left(L_{q} \mid \omega_{q}\right) \cdot f\left(\omega_{q}\right) d \omega_{q}
$$

where $f\left(\omega_{q}\right)$ is the density function of the multivariate normal distribution function with a mean vector of zero and covariance matrix $\Sigma$.

We use Halton-sequence based Quasi Monte Carlo simulation methods (Bhat, 2001) to evaluate the five-dimensional integral to compute the likelihood function in Equation 11. The parameters are estimated using the maximum (log) simulated likelihood (MSL) estimation procedure.

It is useful to note here that the multiple discrete-continuous structure discussed above represents an extension of the "reduced form"-based approach for modeling a single discrete-continuous choice [see Mannering and Hensher (1987) for a discussion of alternate methods for modeling discrete-continuous choices and Bhat (2001) for an application of the reduced-form based approach for the modeling of a single discrete- 
continuous choice]. An alternative approach for modeling such multiple discretecontinuous choices is using the MDCEV structure proposed by Bhat (2005). The MDCEV model, unlike the proposed approach (i.e., the multiple binary-logit/linearregression discrete-continuous model), is theoretically grounded on the principle of utility maximization, captures satiation effects explicitly in the modeling of the continuous choice, and can be expected to be considerably parsimonious in the number of parameters to be estimated. The value of the proposed approach, however, lies in its ability to accommodate more flexible linkages between the discrete and continuous choice components compared to the MDCEV approach.

\section{EMPIRICAL MODEL RESULTS}

This section of the paper discusses the empirical model results. The primary source of data used in this analysis is the 2000 San Francisco Bay Area Travel Survey (MORPACE, 2002). The final sample for analysis comprises weekday activity-travel data for 5381 active, nuclear family, households. Such households include at least one employed adult, comprise a male-female couple, and children, if present are all $\leq 15$ years of age.

For ease in presentation, the five discrete components (decisions to undertake discretionary activities) are discussed first, followed by a discussion of the corresponding continuous components (activity duration). The error correlations are described in the end. The reader is referred to Srinivasan (2004) for additional details and discussions on the empirical results.

It is useful to point out here that empirical and practical considerations required imposing a particular structure to the covariance matrix, $\Sigma$. Nonetheless, the estimated multiple discrete-continuous model with this covariance matrix structure was found to be better than independent discrete-continuous models (the log-likelihood value at 
convergence for the joint model is -27957.20 while the corresponding value for independent models is -28189.229$)$. The log-likelihood value at convergence for a constants-only model is -33728.59 , resulting in an adjusted likelihood ratio index of 0.166 for the final model specification.

\section{Discrete Components: Decisions to Undertake Discretionary Activities}

The results for the discrete components (i.e., the decisions to undertake activities) are presented in Table 1 (Only statistically significant coefficients are included in the table). The explanatory variables are classified into six categories and the impacts of each of these categories of variables are discussed below.

\section{$\underline{\text { Household Characteristics }}$}

The presence of younger children (aged 0 to 10 years) in the household decreases the propensity of men to undertake solo out-of-home activities, while the presence of older children (aged 11 to 15 years) increases the propensity of men to pursue solo in-home activities. Also, adults in households with more children are less likely to undertake joint out-of-home discretionary activities, as indicated by the negative coefficients on all the three children-related variables. Gliebe and Koppelman (2002) also report a similar influence of the presence of children, which is likely to be a reflection of household caretaking and care-sharing responsibilities. Further, we also find that the negative impact of the children of school-going age (i.e., 5-15 years) on the joint activity participation of their parents is stronger than that of younger children (of less than 5 years of age).

Caucasian adults are found to be more likely to undertake independent out-ofhome discretionary activities compared to adults of other ethnicities. Asian women are found to be less likely to undertake out-of-home discretionary activities compared to women of other ethnicities. 
Adults in low-income households are less likely to undertake solo out-of-home discretionary activities, possibly because of monetary budget constraints. In contrast, couples in households with many bicycles are more likely to undertake independent outof-home discretionary activities. The presence of many bicycles in a household could be reflective of an overall out-of-home orientation of the individuals in the household. Women living in their own houses are more likely to undertake out-of-home discretionary activities. Finally, young couples (age of elder household adult $<35$ years) are found to be more likely to undertake joint discretionary activities.

\section{Individual Characteristics}

Age, employment status, student status, and personal vehicle availability are the individual characteristics impacting discretionary-activity participation decisions. Younger adults (both male and female) are less likely to undertake in-home discretionary activities compared to older adults. Similarly, employed adults are also found to be less likely to undertake in-home discretionary activities and male students are less likely to undertake out-of-home discretionary activities during the day, possibly because of overall time constraints imposed by the work and school activities respectively. Finally, the availability of a personal vehicle increases the propensity of both men and women to undertake independent out-of-home activities, a finding also reported by Gliebe and Koppelman (2002). Further, we find that the impact of this variable for men is greater than for women.

\section{Day of the Week and Season Variables}

The next set of variables captures the effects of the day-of-the-week and seasonof-the-year on discretionary activity participation. Men and women are found not to prefer the mid-week (i.e., Wednesdays) for in-home discretionary activities. Fridays are preferred for joint out-of-home discretionary activities, as one would expect at the end of the work-week. Men and women are more likely to undertake in-home discretionary 
activities during summer (June, July, and August). Finally, for reasons not readily apparent, men are also found to be less likely to undertake independent out-of-home activities during the Fall (September, October, and November), and joint activities are found to be less preferred during Spring (March, April, and May).

\section{Mandatory Activity Participation Characteristics}

Next, we examine the impact of mandatory activity participation characteristics on discretionary activity generation decisions. In-home and out-of-home work and escorting children to and from school are considered as mandatory activities in this analysis.

Increasing time investments in in-home work during the day decreases the propensity of both men and women to undertake solo in-home discretionary activities. On examining the impact on out-of-home discretionary activities, we find that men and women who work in-home for fewer than 4 hours are the most likely to undertake out-ofhome discretionary activities (perhaps because of lesser overall time constraints) and those working between 4 and 8 hours are least likely to undertake out-of-home discretionary activities. Adults who work in-home for longer than 8 hours (the base category, with a coefficient of zero) are found to be more likely to undertake solo out-ofhome discretionary activities than those working between 4 and 8 hours. Perhaps, a very long time investment in in-home work motivates undertaking out-of-home activities for relaxation. These results suggest that home-based telecommuting can impact the overall discretionary activity participation behavior in different ways depending on the duration spent in in-home work. The discretionary activity choices of individuals are also impacted by the in-home work characteristics of their spouses. Specifically, when the husband spends long durations (more than 8 hours) in in-home work, his wife is less likely to pursue activities in-home and more likely to undertake out-of-home activities. When the 
wife spends more than four hours in in-home work, her husband is less likely to undertake in-home discretionary activities.

Out-of-home work activities of the household heads also significantly impact their overall discretionary activity choices. Household adults are found to be less likely to undertake discretionary activities jointly, if one or both of them go to work. The propensity to undertake joint activities further decreases with increase in work duration of the spouse beyond 8 hours. In addition, individuals who work for less than eight hours more likely to undertake independent out-of-home discretionary activities and so are their spouses. The implication of these empirical results is that travel demand management policy actions, such as flexible work hours, compressed work week, and home-based telecommuting that influence the work duration of a person can also impact the in-home and out-of-home discretionary activity participation choices of the spouse, resulting in changes to the overall travel patterns of both household adults.

The commute duration is also found to decrease the propensity of both men and women to undertake independent discretionary activities, both in-home and out-of-home, perhaps reflecting the impact of overall time constraints.

Finally, men who undertake serve-passenger activities to escort their children to/from school are also more likely to undertake independent out-of-home discretionary activities (However, these activities are also found to be of shorter durations). If a woman undertakes serve-child activities, then she is less likely to participate in discretionary activities jointly with her husband, possibly as a consequence of the spatial and temporal constraints imposed by the escort responsibilities.

\section{$\underline{\text { In-Home Maintenance Activity Participation Characteristics }}$}

In the overall, increasing personal time investments in in-home maintenance (household chores such as cooking and cleaning) decreases the propensity of the adults to undertake independent discretionary activities both in-home and out-of-home. This 
negative impact of in-home maintenance time on independent in-home discretionary activities is stronger for employed women compared to unemployed women (i.e., an employed woman is less likely to undertake in-home discretionary activities compared to an unemployed woman, given that they spend equal times in in-home maintenance). In addition, in-home maintenance characteristics of adults also influence the solo in-home discretionary activity participation choices of their spouses and the joint out-of-home discretionary activity pursuits. Specifically, a person is more likely to undertake in-home discretionary activities if his/her spouse spends little time (less than 2 hours) in household chores (possibly leading to joint participation of the couple in in-home activities) and adults in households in which the female spends more than 10 hours in household chores are less likely to undertake joint discretionary activities.

\section{Out-of-Home Maintenance Activity Participation Characteristics}

The next set of variables relates to the out-of-home maintenance (grocery shopping) activity decisions of the household. Men and women who undertake shopping for the household are also more likely to undertake independent out-of-home discretionary activities during the day and adults undertaking joint shopping are also more likely to engage in joint discretionary activities. Perhaps the out-of-home discretionary activities in these cases are chained with the shopping episode as shopping centers also offer opportunities for pursuing discretionary activities such as meals and non-maintenance shopping.

\section{Continuous Components: Activity Durations}

The results for the continuous components (i.e., the activity durations) are

presented in Table 2. The explanatory variables are classified into six categories and the impacts of each of these categories of variables are discussed below.

\section{$\underline{\text { Household and Individual Characteristics }}$}


The household characteristics impacting the duration of discretionary activities are the household income, housing tenure, and the number of bicycles. Men in low- and medium-income households spend more time in in-home discretionary activities compared to men in higher income (income $>\$ 100 \mathrm{~K}$ ) households. Adults living in their own houses spend more time in joint out-of-home discretionary activities than those who live in rental units. Finally, the number of bicycles in a household has a negative impact on the female's in-home discretionary time investment and a positive impact on the joint out-of-home time investments of the household adults. The individual-level characteristics impacting the duration of discretionary activities are the employment and student status. Women who are employed or are students are estimated to spend lesser time in in-home and out-of-home independent discretionary activities, as would be expected.

\section{Spatial Variables}

Working adults who have greater accessibility to activity centers from their work zone spend more time in independent out-of-home discretionary activities (the accessibility measures were computed using the Hansen-type log-sum functional form with the retail and service employment levels capturing attraction and the inter-zonal auto IVTT capturing impedance; see Srinivasan, 2004 for further details). Perhaps, as a consequence of the greater accessibility, adults are able to travel to these activity centers quickly and consequently have greater time available for activity participation. We also explored the impact of accessibility to opportunities from the home zone. However, these variables were not statistically significant.

\section{Day-of-the-Week Variables}

The male's discretionary activity duration is found to vary by the day-of-the-week. Specifically, independent out-of-home discretionary activities undertaken on Mondays, 
and in-home discretionary activities undertaken on Thursdays are found to be of shorter durations.

\section{Mandatory Activity Participation Characteristics}

Next, we examine the impact of the mandatory activity participation characteristics. As expected, increasing time investments in in-home work decreases the person's independent discretionary activity durations, both in-home and out-of-home reflecting overall time constrains within which daily activity-travel is pursued. In addition, the wife's in-home work duration also negatively impacts her husband's independent out-of-home discretionary time investments and the household's joint discretionary activity duration.

Increasing out-of-home work time investments is also found to decrease solo discretionary activity durations. Further, non-linear spline-type effects are found in the impact of this out-of-home work duration on discretionary activity duration (except in the case of male's solo out-of-home duration). These non-linear effects indicate that the rate of decrease of discretionary activity duration with increase in work duration is the maximum for work durations between 4 and 8 hours. Finally, increasing time investments of the wife in out-of-home work is found to decrease her husband's discretionary time investment both in-home and out-of-home, possibly because of the increased responsibility of the husband in the overall upkeep of the household. The wife's commute duration also has a negative, non-linear impact on her in-home discretionary activity duration.

Women undertaking serve-child activities to escort children to and from school are found to spend less time in discretionary activities both in-home and out-of-home. Such women are also found to spend more time in joint out-of-home discretionary activities. Note that adults from households in which the wife undertakes serve-child activities are, in general, less likely to undertake joint activities. Thus, the overall model 
suggests that child-care responsibilities may deter parents from pursuing joint activities, but should they decide to undertake joint discretionary activities, the duration of activity participation tends to be longer. Perhaps, the joint activity in such cases is undertaken along with the children or, alternatively, is undertaken by only the spouses after making suitable arrangements for child-care. Finally, men who undertake serve-child activities are found to spend lesser time in out-of-home discretionary activities. However, such men are also more likely to undertake independent out-of-home discretionary activities. Hence, the overall model suggests that men escorting their children to/from school are likely to undertake short-duration out-of-home discretionary activities.

The reader will note that serve-child related variables discussed here have one effect on the discrete component of the choice and the opposite effect on the continuous component of the choice. Such impacts cannot be captured in Tobit-type discretecontinuous models in which the discrete component of the choice is not explicitly modeled.

\section{$\underline{\text { In-Home Maintenance Activity Participation Characteristics }}$}

The in-home maintenance activity duration of a person has an overall negative and non-linear impact on the independent in-home and out-of-home duration choices of household adults. In the case of women, this impact on in-home independent activity durations is found to be different for employed and unemployed persons. Further, the wife's in-home maintenance time investments also positively influence the out-of-home discretionary duration of her husband, i.e., the lesser the time invested by the wife in inhome maintenance chores, the lesser is the husband's out-of-home discretionary activity duration. Finally, the in-home maintenance duration of the adults is also found to impact the joint out-of-home discretionary durations. Specifically, if men undertake in-home chores for more than 6 hours, the duration of the joint activity is found to be shorter. However, women who spend long durations (greater than 10 hours) in household chores 
are found to undertake joint activities with her spouse for longer durations. The reader will note that, adults in households in which the woman spends a very long time in household chores are also less likely to undertake joint discretionary activities. This is another example of a variable with opposing effects on the discrete and continuous components of the overall choice.

\section{Out-of-Home Maintenance Activity Participation Characteristics}

The time invested in solo shopping by a person is found to negatively impact his/her independent out-of-home discretionary duration. The time invested in joint shopping is found to decrease both independent and joint discretionary activity durations (except in the case of female's in-home activities where there is no statistically significant effect). Thus, the overall implication is that, when participation in shopping positively influences out-of-home discretionary activity participation (see discussion in Section 4.1.6), the time invested in shopping constrains the duration of these discretionary activities.

\section{Error Correlations}

We found strong correlations between the discrete and the continuous components of the choices (i.e., $\rho_{i}$ ) in all the five cases (see the last row in Table 2). Note that the error term $\varepsilon_{i q}$ enters the utility expression in Equation 1 with a negative sign. Therefore, a positive sign on the estimated correlation coefficient, as obtained, indicates that unobserved factors that increase the propensity to undertake discretionary activities also decrease the activity duration. A plausible perspective on this result is that the individuals who desire to spend lesser time in discretionary activities are also the ones who are more likely to undertake discretionary activities, as shorter discretionary activities can be more easily accommodated within the overall weekday time constraints. 
Next, we discuss the error correlations across the five choices (i.e., $\Sigma$ ). The results indicate strong positive correlations between the male and female in-home solo activity participation choices and similarly between the male and female solo out-ofhome activity participation choices (The correlation matrix is available in Srinivasan, 2004). These suggest that common unobserved factors (including habits, life-style, and influence) favoring independent discretionary activity participation of the husband also favors independent discretionary activity participation of the wife, both in-home and outof-home. We also found negative correlations between the pairs of error terms corresponding to Male- $\mathrm{IH}$ and Male-OH, Male- $\mathrm{IH}$ and Female-OH, Female- $\mathrm{IH}$ and Female-OH, and Female- $\mathrm{HH}$ and Male-OH suggesting intra-personal and inter-personal substitution effects between independent in-home and out-of-home activity participation choices of the household adults. Finally, the correlations between Male-IH and Joint-OH, and Female- $\mathrm{IH}$ and Joint-OH are negative. This indicates that unobserved factors that increase the propensity for independent in-home activity participation (such as life-style and availability of in-home facilities) also decrease the propensity for joint activity out-ofhome participation. The correlations between the remaining two pairs of error terms (i.e., Male-OH and Joint-OH, and Female-OH and Joint-OH) were estimated to be negative but not statistically significant.

\section{SUMMARY}

This paper presented an analysis of discretionary time-use decisions of couples in active, nuclear family, households. A flexible, multiple-discrete-continuous, econometric structure was developed that captures intra-personal and inter-personal trade-offs, and recognizes the impacts of common unobserved factors on the decisions of the spouses. The model was estimated using data from the 2000 Bay Area Travel Survey. 
Overall, the empirical findings from this research highlight the importance of explicitly incorporating intra-household inter-dependencies for realistic policy evaluations. For example, we find that changes to the work and commute patterns of one person can also impact the independent discretionary activities of his/her spouse and the decisions of the couple to pursue activities jointly (See Srinivasan, 2004 for detailed results of such policy-evaluation analysis undertaken using the estimated models). These effects cannot be captured by travel models which model individuals independently.

There are several interesting avenues for further research. Most of the research to date has focused on joint activity engagement of spouses in two-adult households. Future studies should aim to analyze joint activity participation of parents with children and the joint activity engagement of multiple adults in larger households. Further, it is also important to study joint activities undertaken during weekend days when the relative lack of work- and school-related time constraints may be more favorable for such

pursuits. Another key area of research is to design surveys to enable explicit recording of joint activities and the characteristics of the activity participants.

\section{ACKNOWLEDGEMENTS}

The authors appreciate the comments of four anonymous reviewers on a previous version of the paper. The second author would like to dedicate his part of the research efforts to his Father, Dr. Ramalinga Bhat, who passed away in May 2005. 


\section{REFERENCES}

Bhat, C. R. (2005) A Multiple Discrete Continuous Extreme Value Model: Formulation and Application to Discretionary Time-Use Decisions. Transportation Research Part B, Vol. 39, pp. 679-707.

Bhat, C. R. (2001) Quasi-Random Maximum Simulated Likelihood Estimation of the Mixed Multinomial Logit Model. Transportation Research Part B, Vol. 35, pp. 677-693.

Bhat, C. R. (2001) Modeling the Commute Activity-Travel Pattern of Workers:

Formulation and Empirical Analysis. Transportation Science, Vol. 35, No. 1, pp. 61-79.

Gliebe, J.P. and Koppelman, F.S. (2002) A Model of Joint Activity Participation Between Household Members. Transportation, Vol. 29, pp. 49-72.

Gliebe, J.P. and Koppelman, F.S. (2005) Modeling Household Activity-Travel Interactions as Parallel Constrained Choices. Transportation, Vol. 32, pp. 449-471.

Goulias, K. G. and Kim, T. G. (2005) An Analysis of Activity-Type Classification and Issues Related to the With Whom and For Whom Questions of an Activity Diary. In Timmermans, H. J. P. Progress in Activity-Based Analysis, Elsevier, Oxford, England.

Lee, L. F. (1983) Generalized Econometric Models with Selectivity. Econometrica, Vol. 51, pp. 507-512.

Mannering, F. and Hensher, D. (1987) Discrete/Continuous Econometric Models and Their Application to Transport Analysis. Transport Reviews, Vol. 7, No 3, pp 227-244.

MORPACE International, Inc. (2002) Bay Area Travel Survey Final Report. ftp://ftp.abag.ca.gov/pub/mtc/plannng/BATS/BATS2000/ 
Pribyl, O. and Goulias, K. G. (2005) Simulation of Daily Activity Patterns. In

Timmermans, H. J. P. Progress in Activity-Based Analysis, Elsevier, Oxford, England.

Scott, D. M., and Kanaroglou, P. S. (2002) An Activity-Episode Generation Model that Captures Interactions Between Household Heads: Development and Empirical Analysis. Transportation Research Part B, Vol. 36, pp. 875-896.

Srinivasan, K. K. and Athuru, S. R. (2005) Analysis of Within-Household Effects and Between Household Differences in Maintenance Activity Allocation. Transportation, Vol. 32, pp. 495-521.

Srinivasan, S. (2004) Modeling Household Interactions in Daily Activity Generation. PhD Dissertation, Department of Civil Engineering, The University of Texas at Austin.

Srinivasan,S. and Bhat, C.R. (2005) Modeling Household Interactions in Daily In-Home and Out-of-Home Maintenance Activity Participation. Transportation, Vol. 32, pp. 523544.

Vovsha, P., Bradley, M. and Bowman, J. L. (2005) Activity-Based Travel Forecasting Models in the United States: Progress since 1995 and Prospects for the Future. In Timmermans, H. J. P. Progress in Activity-Based Analysis, Elsevier, Oxford, England.

Vovsha, P., Peterson, E., and Donnelly, R. (2003) Explicit Modeling of Joint Travel by Household Members: Statistical Evidence and Applied Approach. Transportation Research Record No. 1831, pp.1-10. 


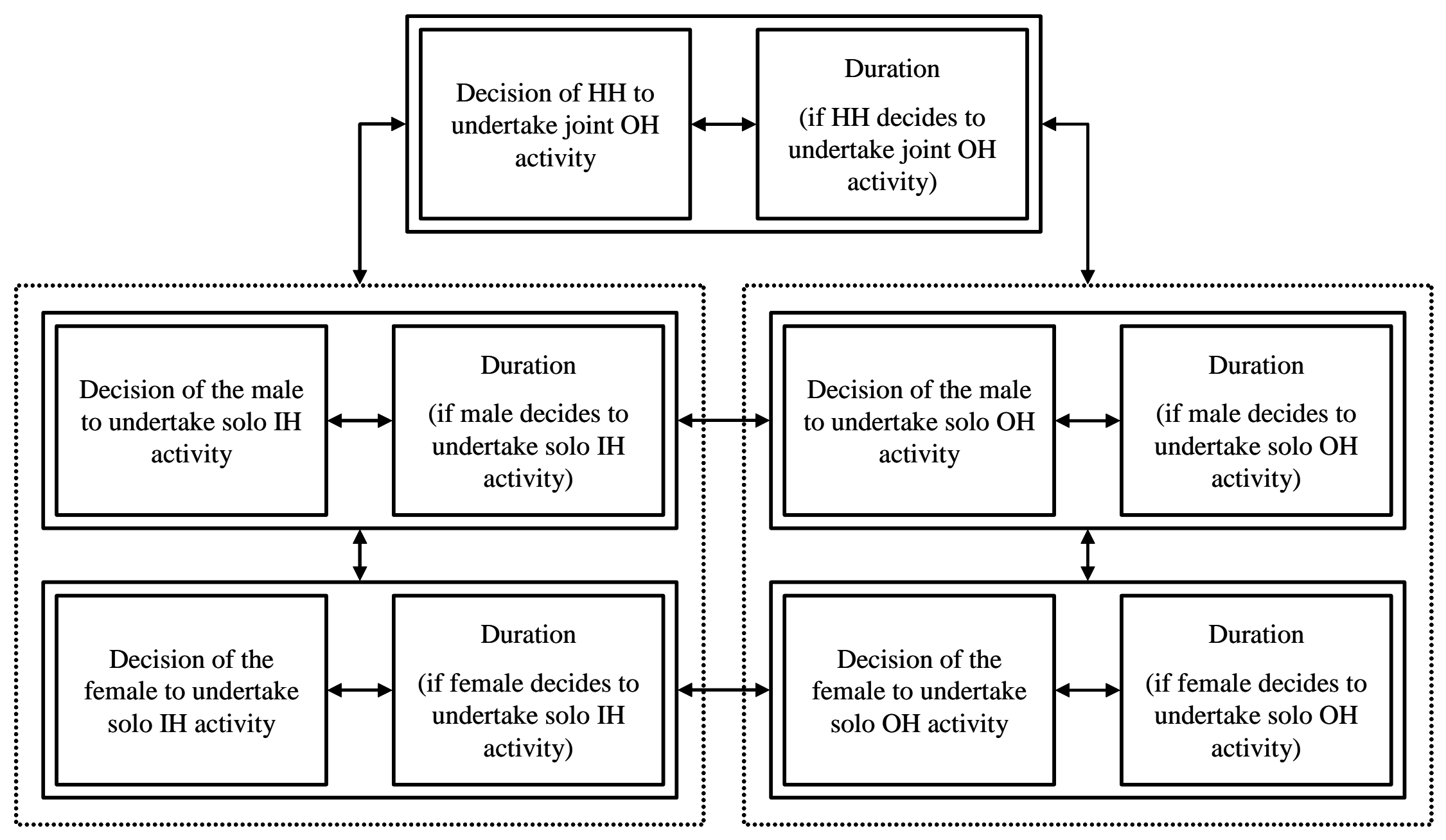

FIGURE 1 Modeling framework for discretionary activity participation choices. 
TABLE 1 Empirical Model Results: Decision to Undertake Activities

\begin{tabular}{|c|c|c|c|c|c|c|c|c|c|c|}
\hline & \multicolumn{2}{|c|}{ Male, IH } & \multicolumn{2}{|c|}{ Female, $\mathrm{IH}$} & \multicolumn{2}{|c|}{ Male, $\mathrm{OH}$} & \multicolumn{2}{|c|}{ Female, $\mathrm{OH}$} & \multicolumn{2}{|c|}{ Joint, $\mathrm{OH}$} \\
\hline & Beta & t. stat. & Beta & t. stat. & Beta & t. stat. & Beta & t. stat. & Beta & t. stat. \\
\hline & & & & & & & & & & \\
\hline Constant & -1.068 & -6.740 & -1.679 & -16.454 & -0.595 & -5.021 & -0.432 & -3.256 & -2.034 & -14.946 \\
\hline \multicolumn{11}{|l|}{ (1) Houshold Characteristics } \\
\hline \multicolumn{11}{|l|}{ Presence of Children } \\
\hline Number of kids aged 0 to 4 & - & - & - & - & -0.114 & -2.530 & - & - & -0.183 & -2.533 \\
\hline Number of kids aged 5 to 10 & - & - & - & - & -0.131 & -2.565 & - & - & -0.262 & -2.812 \\
\hline Number of kids aged 11 to 15 & 0.155 & 1.771 & - & - & - & - & - & - & -0.257 & -2.220 \\
\hline \multicolumn{11}{|l|}{ Ethnicity } \\
\hline Caucasian & - & - & - & - & 0.326 & 5.184 & 0.121 & 1.462 & - & - \\
\hline Asian & - & - & - & - & - & - & -0.435 & -3.907 & - & - \\
\hline \multicolumn{11}{|l|}{ Other } \\
\hline Low income & - & - & - & - & -0.273 & -4.507 & -0.388 & -4.774 & - & - \\
\hline Number of bicycles & - & - & - & - & 0.047 & 2.586 & 0.068 & 3.705 & - & - \\
\hline Own house & - & - & - & - & - & - & 0.250 & 3.640 & - & - \\
\hline Young household & - & - & - & - & - & - & & & 0.287 & 3.217 \\
\hline \multicolumn{11}{|l|}{ (2) Individual Characteristics } \\
\hline \multicolumn{11}{|l|}{ Age } \\
\hline Male aged 16 to 35 years & -0.644 & -6.024 & - & - & - & - & - & - & - & - \\
\hline Male aged 36 to 50 years & -0.469 & -5.024 & - & - & - & - & - & - & - & - \\
\hline Female aged 16 to 35 years & - & - & -0.229 & -2.856 & - & - & - & - & - & - \\
\hline Employment/Student Status & & & & & & & & & & \\
\hline Male is employed & -0.624 & -3.811 & - & - & - & - & - & - & - & - \\
\hline Female is employed full time & - & - & -0.233 & -2.371 & - & - & - & - & - & - \\
\hline Male is a student & - & - & - & - & -0.309 & -3.340 & - & - & - & - \\
\hline Vehicle availability & & & & & & & & & & \\
\hline Male's personal vehicle availability & - & - & - & - & 0.357 & 4.313 & - & - & - & - \\
\hline Female's personal vehicle availability & - & - & - & - & - & - & 0.167 & 1.892 & - & - \\
\hline \multicolumn{11}{|c|}{ (3) Day-of the-Week and Season Variables } \\
\hline \multicolumn{11}{|l|}{ Day of the Week } \\
\hline Wednesday & -0.197 & -2.068 & -0.202 & -2.242 & - & - & - & - & - & - \\
\hline Friday & - & - & - & - & 0.049 & 0.730 & - & - & 0.494 & 4.952 \\
\hline \multicolumn{11}{|l|}{ Season of the Year } \\
\hline Summer & 0.287 & 3.326 & 0.188 & 2.308 & - & - & - & - & - & - \\
\hline Fall & - & - & - & - & -0.102 & -1.954 & - & - & - & - \\
\hline Spring & - & - & - & - & - & - & - & - & -0.336 & -3.997 \\
\hline
\end{tabular}


TABLE 1 (Continued) Empirical Model Results: Decision to Undertake Activities

\begin{tabular}{|c|c|c|c|c|c|c|c|c|c|c|}
\hline & \multicolumn{2}{|c|}{ Male, IH } & \multicolumn{2}{|c|}{ Female, IH } & \multicolumn{2}{|c|}{ Male, $\mathrm{OH}$} & \multicolumn{2}{|c|}{ Female, $\mathrm{OH}$} & \multicolumn{2}{|c|}{ Joint, $\mathrm{OH}$} \\
\hline & Beta & t. stat. & Beta & t. stat. & Beta & t. stat. & Beta & t. stat. & Beta & t. stat. \\
\hline \multicolumn{11}{|c|}{ (4) Mandatory Activity Participation Characterisitics } \\
\hline \multicolumn{11}{|l|}{ In-Home Work } \\
\hline Male's IH work dur. $<=4$ hours & - & - & - & - & 0.762 & 4.539 & - & - & - & - \\
\hline Male's IH work dur. $<=8$ hours & 0.746 & 4.494 & 0.312 & 2.146 & -0.539 & -3.601 & -0.291 & -2.127 & - & - \\
\hline Female's IH work dur. $<=4$ hours & 0.605 & 2.247 & 1.082 & 3.659 & - & - & 0.703 & 3.441 & - & - \\
\hline Female's IH work dur. $<=8$ hours & - & - & - & - & - & - & -0.496 & -2.956 & - & - \\
\hline \multicolumn{11}{|l|}{ Out-of-Home Work } \\
\hline Male goes to work & - & - & - & - & - & - & - & - & -0.917 & -9.168 \\
\hline Male's $\mathrm{OH}$ work dur. $<=4$ hours & 0.598 & 2.975 & - & - & - & - & - & - & - & - \\
\hline Male's $\mathrm{OH}$ work dur. $<=8$ hours & 0.853 & 7.324 & - & - & 1.007 & 13.937 & 0.158 & 2.270 & 0.515 & 5.515 \\
\hline Female goes to work & - & - & - & - & - & - & - & - & -0.681 & -6.857 \\
\hline Female's $\mathrm{OH}$ work dur. $<=4$ hours & - & - & 1.096 & 5.816 & - & - & - & - & 0.445 & 2.460 \\
\hline Female's $\mathrm{OH}$ work dur. $<=8$ hours & - & - & 0.586 & 4.995 & 0.162 & 2.454 & 0.922 & 10.124 & - & - \\
\hline \multicolumn{11}{|l|}{ Commute } \\
\hline LN(commute duration) for Male & -0.449 & -15.333 & - & - & -0.265 & -13.598 & - & - & - & - \\
\hline LN(commute duration) for Female & - & - & -0.399 & -11.353 & - & - & -0.294 & -11.718 & - & - \\
\hline \multicolumn{11}{|l|}{ Escort Child to/from School } \\
\hline Male undertakes escort activity & - & - & - & - & 0.306 & 2.320 & - & - & - & - \\
\hline Female undertakes escort activity & - & - & - & - & - & - & - & - & -0.373 & -1.761 \\
\hline \multicolumn{11}{|c|}{ (5) In-Home Maintenance Activity Participation Characterisitics } \\
\hline \multicolumn{11}{|l|}{ Male's IH maintenance activities } \\
\hline IH maint. dur. $<=2$ hours & 2.861 & 24.307 & 0.511 & 6.550 & - & - & - & - & - & - \\
\hline IH maint. dur. $<=6$ hours & 1.353 & 12.031 & - & - & 0.191 & 3.195 & - & - & - & - \\
\hline $\mathrm{H}$ maint. dur. $<=10$ hours & 1.539 & 11.885 & - & - & - & - & & & - & - \\
\hline Female's IH maintenance activities & & & & & & & & & & \\
\hline $\mathrm{IH}$ maint. dur. $<=2$ hours & 0.450 & 4.254 & 2.379 & 16.499 & - & - & - & - & - & - \\
\hline IH maint. dur. $<=6$ hours & - & - & 1.361 & 12.141 & - & - & - & - & - & - \\
\hline IH maint. dur. $<=10$ hours & - & - & 1.250 & 9.770 & - & - & 0.379 & 4.509 & 0.594 & 4.219 \\
\hline IH maint. dur. $<=2$ hours * Unemployed & - & - & -1.886 & -4.729 & - & - & - & - & - & - \\
\hline IH maint. dur. $<=10$ hours * Unemployed & 0.230 & 1.857 & 0.910 & 5.430 & - & - & - & - & - & - \\
\hline \multicolumn{11}{|c|}{ (6) Out-of-Home Maintenance Activity Participation Characterisitics } \\
\hline Male shops & - & - & - & - & 0.765 & 5.513 & - & - & - & - \\
\hline Female shops & - & - & 0.223 & 1.986 & - & - & 0.723 & 6.837 & - & - \\
\hline Joint shopping & 0.485 & 1.472 & - & - & - & - & -0.481 & -1.590 & 2.785 & 9.550 \\
\hline
\end{tabular}


TABLE 2 Empirical Model Results: Activity Durations

\begin{tabular}{|c|c|c|c|c|c|c|c|c|c|c|}
\hline & \multicolumn{2}{|c|}{ Male, $\mathrm{IH}$} & \multicolumn{2}{|c|}{ Female, $\mathrm{IH}$} & \multicolumn{2}{|c|}{ 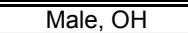 } & \multicolumn{2}{|c|}{ Female, $\mathrm{OH}$} & \multicolumn{2}{|c|}{$=$ Joint, $\mathrm{OH}$} \\
\hline & Beta & t. stat. & Beta & t. stat. & Beta & t. stat. & Beta & t. stat. & Beta & t. stat. \\
\hline Constant & 5.704 & 107.848 & 20.224 & 10.174 & 16.530 & 6.712 & 12.312 & 7.425 & 6.109 & 48.172 \\
\hline \multicolumn{11}{|l|}{ (1) Houshold and Individual Characteristics } \\
\hline Income & & & & & & & & & & \\
\hline Low income & 0.094 & 2.592 & - & - & - & - & - & - & - & - \\
\hline Medium income & 0.066 & 2.189 & - & - & - & - & - & - & - & - \\
\hline \multicolumn{11}{|l|}{ Other Household Characteristics } \\
\hline Own house & - & - & - & - & - & - & - & - & 0.137 & 2.037 \\
\hline Number of bicycles & - & - & -0.022 & -2.296 & - & - & - & - & 0.064 & 2.898 \\
\hline Female is employed & - & - & -7.468 & -3.406 & - & - & - & - & - & - \\
\hline Female is full-time student & - & - & -0.166 & -1.708 & - & - & -0.365 & -3.262 & - & - \\
\hline Female is part-time student & - & - & -0.096 & -1.697 & - & - & - & - & - & - \\
\hline \multicolumn{11}{|l|}{ (2) Spatial Variables } \\
\hline Male's accessibility to activity centers from work & - & - & - & - & 0.651 & 4.489 & - & - & - & - \\
\hline Female's accessibility to activity centers from work & - & - & - & - & - & - & 0.580 & 2.728 & - & - \\
\hline \multicolumn{11}{|l|}{ (3) Day-of the-Week Variables } \\
\hline Monday & - & - & - & - & -0.171 & -3.064 & - & - & - & - \\
\hline Thursday & -0.073 & -2.207 & - & - & - & - & - & - & - & - \\
\hline \multicolumn{11}{|l|}{ (4) Mandatory Activity Participation Characterisitics } \\
\hline \multicolumn{11}{|l|}{ In-Home Work } \\
\hline LN(IH work dur.) of the male & -0.132 & -14.903 & - & - & -0.128 & -7.075 & - & - & - & - \\
\hline $\mathrm{LN}(\mathrm{IH}$ work dur.) of the female & & & -0.137 & -11.862 & -0.022 & -1.485 & -0.120 & -6.830 & -0.057 & -2.568 \\
\hline \multicolumn{11}{|l|}{ Male's Out-of-Home Work } \\
\hline $\mathrm{LN}(\mathrm{OH}$ work dur.) & -0.138 & -22.671 & - & - & -0.329 & -7.593 & - & - & - & - \\
\hline $\mathrm{LN}(\mathrm{OH} \text { work dur. })^{*} \mathrm{OH}$ work dur. $<=4$ hours & 1.016 & 5.984 & - & - & - & - & - & - & - & - \\
\hline $\mathrm{LN}(\mathrm{OH} \text { work dur. })^{*} \mathrm{OH}$ work dur. $<=8$ hours & -0.959 & -6.216 & - & - & - & - & - & - & - & - \\
\hline $\mathrm{OH}$ work dur. $<=4$ hours & -5.755 & -5.871 & - & - & - & - & - & - & - & - \\
\hline $\mathrm{OH}$ work dur. $<=8$ hours & 5.833 & 6.336 & - & - & - & - & - & - & - & - \\
\hline \multicolumn{11}{|l|}{ Female's Out-of-Home Work } \\
\hline $\mathrm{LN}(\mathrm{OH}$ work dur. $)$ & -0.007 & -1.521 & -0.134 & -11.222 & -0.011 & -1.374 & -0.341 & -5.375 & - & - \\
\hline $\mathrm{LN}(\mathrm{OH} \text { work dur. })^{*} \mathrm{OH}$ work dur. $<=4$ hours & - & - & 0.848 & 4.454 & - & 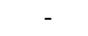 & 0.837 & 3.297 & - & - \\
\hline $\mathrm{LN}(\mathrm{OH} \text { work dur. })^{*} \mathrm{OH}$ work dur. $<=8$ hours & - & - & -0.841 & -4.701 & - & - & -0.523 & -2.141 & - & - \\
\hline $\mathrm{OH}$ work dur. $<=4$ hours & - & - & -4.820 & -4.375 & - & - & -4.521 & -3.070 & - & - \\
\hline OH work dur. $<=8$ hours & - & - & 5.167 & 4.861 & - & - & 3.121 & 2.149 & - & - \\
\hline \multicolumn{11}{|l|}{ Female's Commute } \\
\hline LN $(\text { comm. dur })^{*}$ comm. dur. $<=30$ mins. & - & - & 0.564 & 2.767 & - & - & - & - & - & - \\
\hline LN $(\text { comm. dur })^{*}$ comm. dur. $<=60$ mins. & - & - & -0.508 & -2.665 & - & - & - & - & - & - \\
\hline Comm. dur. $<=30$ mins. & - & - & -2.075 & -2.762 & - & - & - & - & - & - \\
\hline Comm. dur. $<=60 \mathrm{mins}$ & 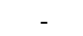 & - & 1.856 & 2.569 & _ & 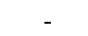 & & - & - & - \\
\hline \multicolumn{11}{|l|}{ Escort Child to/from School } \\
\hline Female undertakes escort activity & - & - & -0.131 & -2.926 & - & - & -0.214 & -3.507 & 0.274 & 1.734 \\
\hline Male undertakes escort activity & 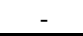 & - & 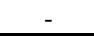 & 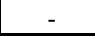 & -0.305 & -2.709 & 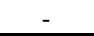 & 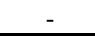 & 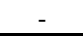 & 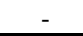 \\
\hline
\end{tabular}


TABLE 2 (Continued) Empirical Model Results: Activity Durations

\begin{tabular}{|c|c|c|c|c|c|c|c|c|c|c|}
\hline & \multicolumn{2}{|c|}{ 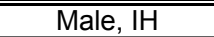 } & \multicolumn{2}{|c|}{ Female, IH } & \multicolumn{2}{|c|}{ Male, $\mathrm{OH}$} & \multicolumn{2}{|c|}{ Female, $\mathrm{OH}$} & \multicolumn{2}{|c|}{ Joint, $\mathrm{OH}$} \\
\hline & Beta & t. stat. & Beta & t. stat. & Beta & t. stat. & Beta & t. stat. & Beta & t. stat. \\
\hline \multicolumn{11}{|c|}{ (5) In-Home Maintenance Activity Participation Characterisitics } \\
\hline Male's IH Maintenance Activities & & & & & & & & & & \\
\hline LN(IH maint. dur.) & - & - & - & - & -1.699 & -4.594 & - & - & - & - \\
\hline $\mathrm{LN}(\mathrm{IH} \text { maint. dur. })^{*} \mathrm{IH}$ maint. dur. $<=2$ hours & 0.862 & 11.877 & - & - & - & - & - & - & - & - \\
\hline $\mathrm{LN}(\mathrm{IH} \text { maint. dur. })^{*} \mathrm{IH}$ maint. dur. $<=6$ hours & -0.928 & -13.017 & - & - & - & - & - & - & - & - \\
\hline LN(IH maint. dur. $)^{*} \mathrm{IH}$ maint. dur. $<=10$ hours & - & - & - & - & 1.646 & 4.449 & - & - & - & - \\
\hline IH maint. dur. $<=2$ hours & -4.392 & -11.319 & - & - & - & - & - & - & - & - \\
\hline IH maint. dur. $<=6$ hours & 5.351 & 13.758 & - & - & - & - & - & - & 0.372 & 4.758 \\
\hline IH maint. dur. $<=10$ hours & & & & & -10.487 & -4.274 & - & - & - & - \\
\hline \multicolumn{11}{|l|}{ Female's IH Maintenance Activities } \\
\hline LN(IH maint. dur.) & - & - & -1.091 & -3.637 & 0.044 & 2.977 & -1.055 & -4.244 & - & - \\
\hline LN(IH maint. dur. $)^{\star} \mathrm{IH}$ maint. dur. $<=2$ hours & - & - & 0.969 & 9.052 & - & - & 0.211 & 3.095 & - & - \\
\hline $\mathrm{LN}(\mathrm{IH} \text { maint. dur. })^{\star} \mathrm{IH}$ maint. dur. $<=6$ hours & - & - & -0.688 & -2.810 & - & - & - & - & - & - \\
\hline LN(IH maint. dur. $)^{*} \mathrm{IH}$ maint. dur. $<=10$ hours & - & - & 0.745 & 2.268 & - & - & 0.881 & 3.457 & - & - \\
\hline IH maint. dur. $<=2$ hours & - & - & -5.064 & -8.858 & - & - & -0.939 & -2.531 & - & - \\
\hline IH maint. dur. $<=6$ hours & - & - & 3.925 & 2.658 & - & - & - & - & - & - \\
\hline IH maint. dur. $<=10$ hours & - & - & -4.868 & -2.304 & - & - & -5.611 & -3.332 & -0.346 & -3.139 \\
\hline Unemployed Female's IH Maintenance Activities & & & & & & & & & & \\
\hline LN(IH maint. dur.) & - & - & -1.109 & -3.343 & - & - & - & - & - & - \\
\hline $\mathrm{LN}(\mathrm{IH} \text { maint. dur. })^{*} \mathrm{IH}$ maint. dur. $<=2$ hours & - & - & -0.699 & -1.989 & - & - & - & - & - & - \\
\hline $\mathrm{LN}(\mathrm{IH} \text { maint. dur. })^{*} \mathrm{IH}$ maint. dur. $<=6$ hours & - & - & 1.892 & 3.835 & - & - & - & - & - & - \\
\hline $\mathrm{LN}(\mathrm{IH} \text { maint. dur. })^{*} \mathrm{IH}$ maint. dur. $<=10$ hours & - & - & -0.084 & -3.126 & - & - & - & - & - & - \\
\hline IH maint. dur. $<=2$ hours & - & - & 3.649 & 1.886 & - & - & - & - & - & - \\
\hline IH maint. dur. $<=6$ hours & - & - & -11.265 & -3.882 & - & - & - & - & - & - \\
\hline \multicolumn{11}{|c|}{ (6) Out-of-Home Maintenance Activity Participation Characterisitics } \\
\hline LN(Male's shopping dur.) & - & - & - & - & -0.222 & -6.166 & - & - & - & - \\
\hline LN(Female's shopping dur.) & - & - & - & - & - & - & -0.184 & -8.715 & - & - \\
\hline LN(joint shopping dur.) & -0.090 & -2.919 & - & - & -0.182 & -3.172 & -0.099 & -1.566 & -0.475 & -7.695 \\
\hline S.D. of Error Term $\left(\sigma_{\eta \mathrm{i}}\right)$ & 0.815 & 94.597 & 0.904 & 70.659 & 1.594 & 63.841 & 1.414 & 64.896 & 1.331 & 40.616 \\
\hline $\begin{array}{l}\text { Correlation Between Discrete and Continuous } \\
\text { Components }\left(\rho_{\mathrm{i}}\right)\end{array}$ & 0.871 & 32.541 & 0.869 & 30.704 & 1.000 & fixed & 0.997 & 211.819 & 1.000 & fixed \\
\hline
\end{tabular}

